\title{
Interventions to reduce the risk of violence toward emergency department staff: current approaches
}

This article was published in the following Dove Press journal:

Open Access Emergency Medicine

2I April 2016

Number of times this article has been viewed

\author{
Nicola Ramacciati ${ }^{1,2}$ \\ Andrea Ceccagnoli ${ }^{2}$ \\ Beniamino Addey ${ }^{3}$ \\ Enrico Lumini ${ }^{4}$ \\ Laura Rasero 1,5 \\ 'Department of Experimental and \\ Clinical Medicine, University of \\ Florence, ${ }^{2}$ Emergency Department, \\ S. Maria della Misericordia Hospital, \\ ${ }^{3}$ Emergency Medical System, S. Maria \\ della Misericordia Hospital, Perugia, \\ ${ }^{4}$ Department of Health Sciences, \\ University of Florence, ${ }^{5}$ Research \\ and Development Unit, Azienda \\ Ospedaliero Universitaria Careggi, \\ Florence, Italy
}

Introduction: The phenomenon of workplace violence in health care settings, and especially in the emergency department (ED), has assumed the dimensions of a real epidemic. Many studies highlight the need for methods to ensure the safety of staff and propose interventions to address the problem.

Aim: The aim of this review was to propose a narrative of the current approaches to reduce workplace violence in the ED, with a particular focus on evaluating the effectiveness of emergency response programs.

Methods: A search was conducted between December 1, 2015 and December 7, 2015, in PubMed and CINAHL. Ten intervention studies were selected and analyzed.

Results: Seven of these interventions were based on sectoral interventions and three on comprehensive actions.

Conclusion: The studies that have attempted to evaluate the effectiveness of interventions have shown weak evidence to date. Further research is needed to identify effective actions to promote a safe work environment in the ED.

Keywords: workplace violence, violence prevention and control, emergency department, aggression, security, review

\section{Introduction}

Every emergency nurse and physician is aware that there exists a dark side to their job: the violence against emergency department (ED) staff. ${ }^{1}$ The "violent acts (including physical assaults and threats of assaults) directed toward persons at work or on duty" are considered by the National Institute of Occupational Safety and Health as workplace violence (WPV), ${ }^{2}$ and this phenomenon in health care settings, and especially in the ED, is so widespread throughout the world that it has assumed the dimensions of a real epidemic. ${ }^{3,4}$ This trend of WPV is continually growing, ${ }^{5,6}$ so that several international organizations, such as the International Labour Office, the International Council of Nurses, the World Health Organization, and Public Services International, have been issuing specific guidelines on this topic for a long time. ${ }^{7}$ A very recent study highlights that more than two-thirds of physicians experienced work-related assaults and $>50 \%$ of physicians suffered WPV in the previous year, ${ }^{8}$ and nurses are even less safe than other ED workers. ${ }^{9}$ WPV affected $90 \%$ of emergency nurses in the previous year. ${ }^{10}$ Table 1 lists the incidence of WPV against emergency personnel reported in some international studies. ${ }^{11-21}$

Due to this high prevalence, violence is regarded worldwide by emergency nurses and physicians as "inevitable", 22 or "part of job". ${ }^{23}$ Whelan ${ }^{5}$ stated that the first documentation
Correspondence: Nicola Ramacciati Emergency Department, S. Maria della Misericordia Hospital, Piazzale Menghini, $8 / 9,06124$ Perugia, Italy

Tel +393938739863

Email nicola.ramacciati@ospedale. perugia.it
Open Access Emergency Medicine 2016:8 17-27

(c) (1) (2) ๑ 2016 Ramaccatiti et al. This work is published and licensed by Dove Medical Press Limited. The full terms of this license are available at https://www.dovepress.com/ cc) work you hereby accept the Terms. Non-commercial uses of the work are permitted without any further permission from Dove Medical Press Limited, provided the work is property attributed. For permission for commercial use of this work, please see paragraphs 4.2 and 5 of our Terms (https://www.doveperess.com/terms.php).
Dovepress

http://dx.doi.org/10.2147/OAEM.S69976 
Table I Incidence of WPV in the ED by year, country, profession, type of violence, and period

\begin{tabular}{|c|c|c|c|c|c|c|c|}
\hline Reference & Year & Country & ED worker & WPV exposure & Verbal violence & Physical violence & Period \\
\hline Wyatt and Watt" & 1995 & UK & 100 physicians & & (96/100) $96 \%$ & (18/100) $18 \%$ & Not indicated \\
\hline Lyneham ${ }^{12}$ & 2000 & Australia & 266 nurses & & (154/266 (58\% & (37/266) $14 \%$ & I week \\
\hline Behnam et $\mathrm{al}^{13}$ & 2011 & USA & 263 physicians & (205/263) $78 \%$ & (197/263) 74.9\% & (56/263) $21.3 \%$ & 12 months \\
\hline Lee $^{14}$ & 2001 & USA & $\mathrm{I}, 400$ nurses & & (I,358/I,400) 97\% & $(I, 218 / 1,400) 87 \%$ & 12 months \\
\hline Crilly et al ${ }^{15}$ & 2004 & Australia & 71 nurses & (50/7I) 70.4\% & (67/7I) 94.3\% & (I7/7I) $23.9 \%$ & 5 months \\
\hline Winstanely and & 2004 & UK & 375 ED staff & & (249/375) 66.4\% & (104/375) $27.7 \%$ & 12 months \\
\hline \multicolumn{8}{|l|}{ Whittington $^{16}$} \\
\hline James et $\mathrm{al}^{17}$ & 2005 & UK & ED staff & 218 episodes & (196/218) 89.9\% & (70/2।8) $32.1 \%$ & 12 months \\
\hline \multirow[t]{2}{*}{ Cezar and Marziale $e^{18}$} & 2006 & Brazil & 33 nurses & (33/33) $100 \%$ & (28/30) 93.3\% & $(5 / 30) 16.7 \%$ & 12 months \\
\hline & & & 14 physicians & (I2/14) $85.7 \%$ & (I2/12) $100 \%$ & (2/12) $16.7 \%$ & 12 months \\
\hline Ryan and Maguire ${ }^{19}$ & 2006 & Ireland & 37 nurses & & (33/37) $89.2 \%$ & (20/37) $54.1 \%$ & I month \\
\hline Pinar and Ucmak ${ }^{20}$ & 2011 & Turkey & 255 nurses & & (233/255 (91.4\% & (190/255) 74.9\% & 12 months \\
\hline Esmaeilpour et $\mathrm{al}^{21}$ & 2011 & Iran & 196 nurses & & (I79/196 $91.6 \%$ & (39/196) $19.7 \%$ & 12 months \\
\hline
\end{tabular}

Abbreviations: ED, emergency department; WPV, workplace violence.

of aggressive encounters from patients and the public toward nurses dates back to 1824 . Violence against emergency staff has also been reported as a problem in countries such as the UK, ${ }^{24}$ Ireland, ${ }^{19}$ Spain, ${ }^{25}$ Italy, ${ }^{26}$ Australia, ${ }^{12}$ Canada, ${ }^{27}$ and the US. ${ }^{28}$ Only in the past year were studies conducted on the issue of assault against emergency staff in Taiwan, ${ }^{8}$ Pakistan, ${ }^{29}$ Jordan, ${ }^{30,31}$ Italy, ${ }^{32}$ US,,${ }^{33-38}$ Norway, ${ }^{39}$ Australia, ${ }^{40}$ Palestine, ${ }^{41}$ Ethiopia, ${ }^{42}$ Iran,${ }^{43}$ Singapore ${ }^{44}$ Cyprus,${ }^{45}$ and France. ${ }^{46}$ These studies, as well as most of those published until now, concern a review of WPV incidence and prevalence in ED, a description of precipitants and risk factors, types of violent acts (verbal or physical), or, in the qualitative studies, an analysis of the experiences and feelings of the staff suffering aggression. Of course, many studies have highlighted the need for methods to ensure the safety of staff and proposed interventions to address the problem. However, in the international literature, documentation of specific actions to address or reduce violence is lacking, ${ }^{47}$ and when these studies do recommend possible solutions, the analysis of intervention effectiveness is often only a secondary consideration $^{48}$ or limited in scope and evaluation. ${ }^{49}$

\section{Purpose}

The aim of our review is to propose a narrative of the current approaches to reduce WPV in the ED, with a particular focus on evaluating the effectiveness of the proposed emergency response programs.

\section{Methods}

In September 2015, a preliminary search of the international literature on the subject of this study was conducted in the PubMed database using the following search terms: "emergency department", "aggression", "workplace violence", "approach", and "intervention". The terms were combined using the Boolean operators OR and AND. This preliminary study allowed us to obtain useful elements for carrying out the "facet analysis" necessary to identify the key terms to be used in the search strategy. The PICO framework was used to develop literature search strategies. Table 2 shows the research question in analytical format. The MeSH terms and the search terms were combined to maximize the sensitivity of the research. In the CINAHL database, the near operators $\mathrm{N} 1$ and N2 were used in order to retrieve records with two terms in the same sentence or multiple words to increase the specificity of the search. Similarly, "search terms" in inverted commas were used in the PubMed database.

The final search was conducted between December 1, 2015 and December 7, 2015, in the PubMed database (the free Medline version) and the CINAHL database (CINAHL Plus with full text, using EBSCO host). Literature were included in this review if the following inclusion criteria were met: 1 ) the article is written in English, French, or Italian; 2) abstracts or full text is available; 3 ) publication date is from January 1, 2011 to December 7, 2015; and 4) workplace intervention is evaluated to prevent occupational violence in the ED.

\section{Results}

The search carried out in PubMed and CINAHL produced 26 studies in the first database and 25 in the second database. The flowchart of Figure 1 shows the selection process. Applying the inclusion and exclusion criteria, we selected ten studies examining the phenomenon of violence against ED staff by evaluating approaches or strategies for the management of aggression.

\section{Discussion}

Through the analysis of the selected publications (Table 3), some approaches to the problem of WPV in the ED emerged. Seven of these approaches are based on sectoral interventions and three on comprehensive actions. 
Table 2 From PICO framework to facet analysis: search terms

\begin{tabular}{|c|c|c|c|c|}
\hline Population & Problem & Intervention & Comparison & Outcome \\
\hline $\begin{array}{l}\text { Health professionals of } \\
\text { emergency department }\end{array}$ & Workplace violence & $\begin{array}{l}\text { Approaches to reducing } \\
\text { violence in ED }\end{array}$ & None & $\begin{array}{l}\text { Safety, violent episode } \\
\text { decrease }\end{array}$ \\
\hline Toward: & Aggression(s) & Approach & & Appraisal \\
\hline Doctor(s) & Aggressive patient(s) & Avoidance & & Assessment \\
\hline ED worker(s) & Attack(s) & Debriefing & & Effectiveness \\
\hline Nurse(s) & Assault(s) & De-escalation & & Evaluation \\
\hline Physician(s) & Threat(s) & Deterrence & & Minimization \\
\hline \multirow[t]{3}{*}{ Staff } & Violence & Educational & & Outcome(s) \\
\hline & Episodes of violence & Intervention(s) & & Protection(s) \\
\hline & Patient-related violence & Management & & Safe working environment \\
\hline Accident and emergency & & Methods of managing & & \\
\hline Emergency service(s) & Physical violence & Policy & & Safety \\
\hline Emergency & Verbal violence & Zero-tolerance policy & & Well-being \\
\hline Department(s) & Violent behavior(s) & Prevention & & \\
\hline $\mathrm{ED}(\mathrm{s})$ & Workplace violence & Program & & \\
\hline \multirow[t]{9}{*}{ Triage } & WPV & Provision & & \\
\hline & & Reduction & & \\
\hline & & Security measures & & \\
\hline & & Strategy(ies) & & \\
\hline & & To manage & & \\
\hline & & To prevent & & \\
\hline & & To provide & & \\
\hline & & To support & & \\
\hline & & Training & & \\
\hline
\end{tabular}

Abbreviations: ED, emergency department; WPV, workplace violence.

\section{Guiding principles for mitigating WPV}

In presenting the current approaches to the problem of WPV in the ED, we believe that it is important to start with the guiding principles and priority focus areas recently developed jointly by the American Organization of Nurse Executives and the Emergency Nurses Association and published in the July editions of both the Journal of Emergency Nursing ${ }^{33}$ and the Journal of Nursing Administration. ${ }^{34}$ Many studies have in fact shown that health professionals often feel unsupported by their institutions and leaders..$^{32,44,50,51}$ For the first time, 13 participants (members of the American Organization of Nurse Executives and Emergency Nurses Association) at the

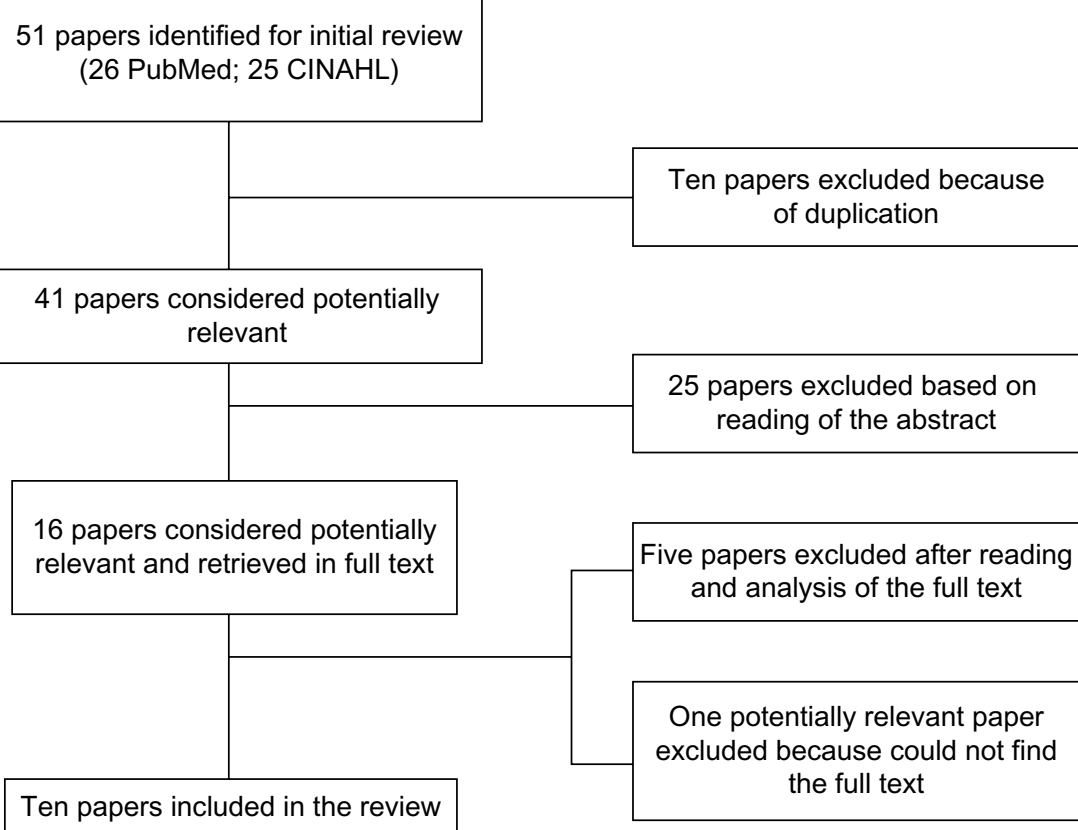

Figure I Flowchart of selection process. 


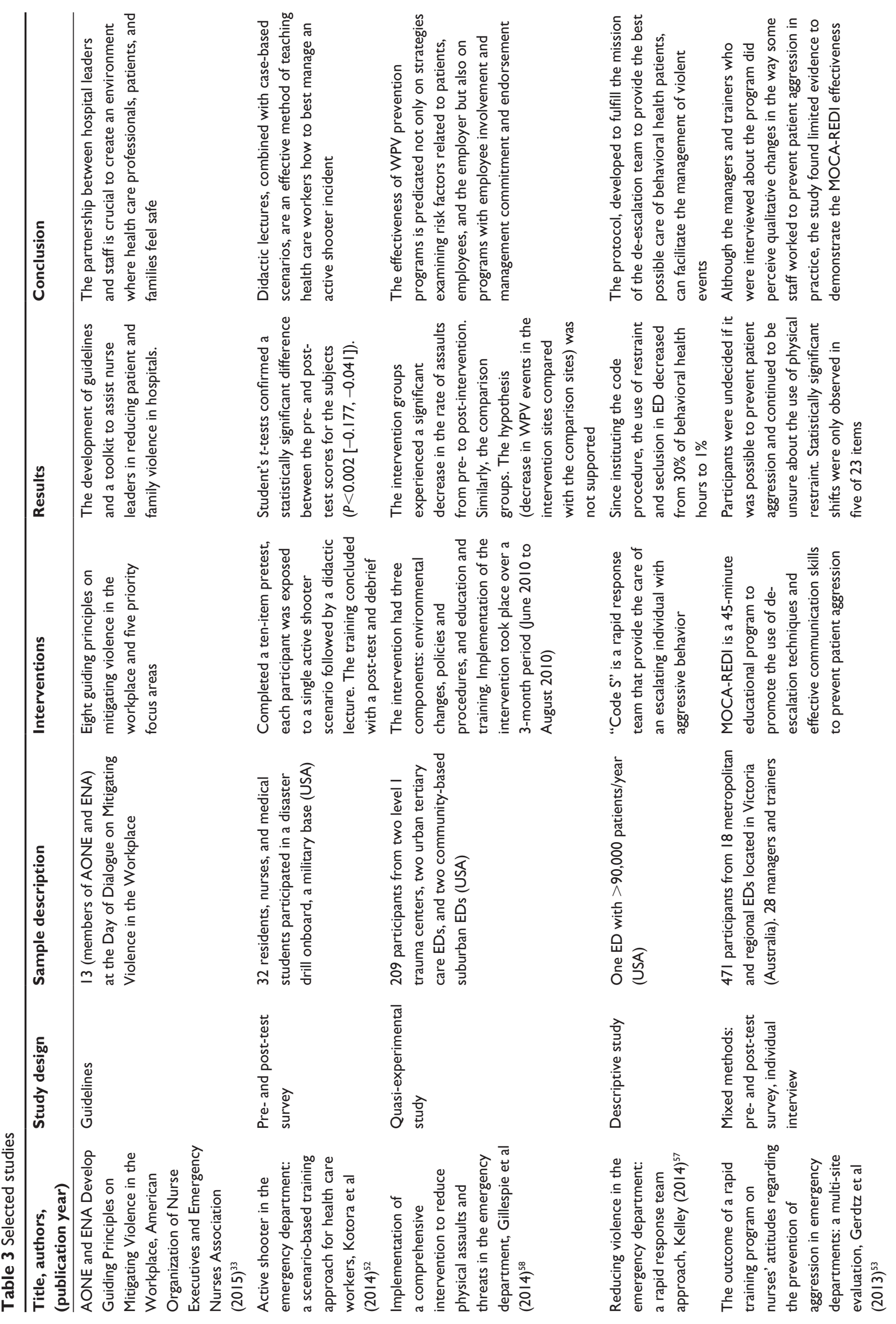




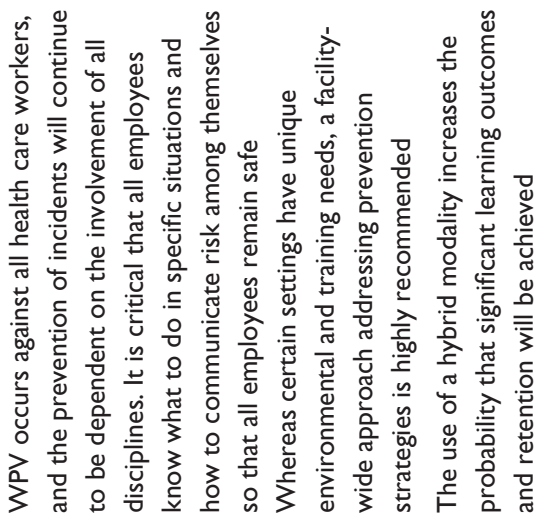
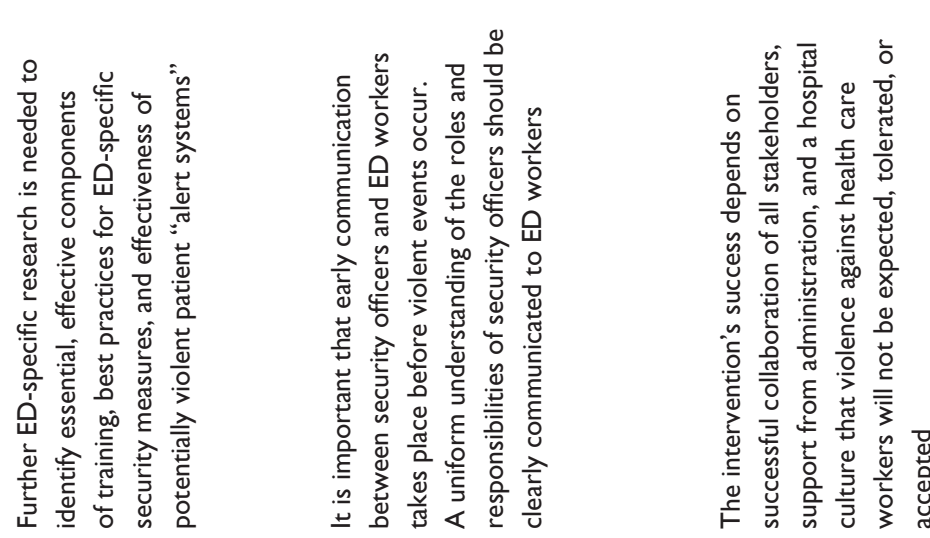

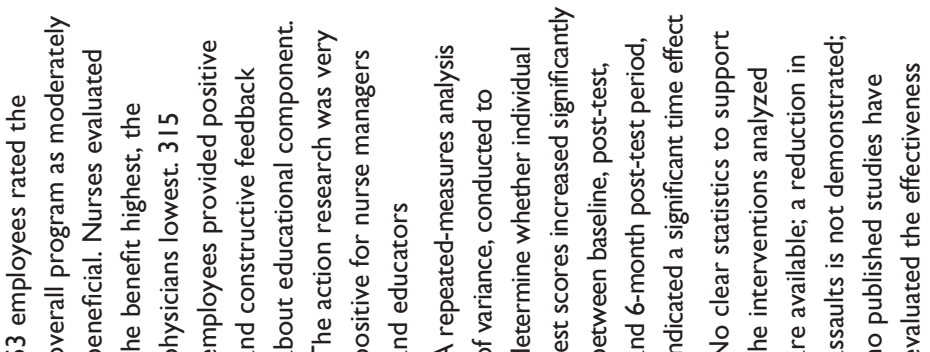

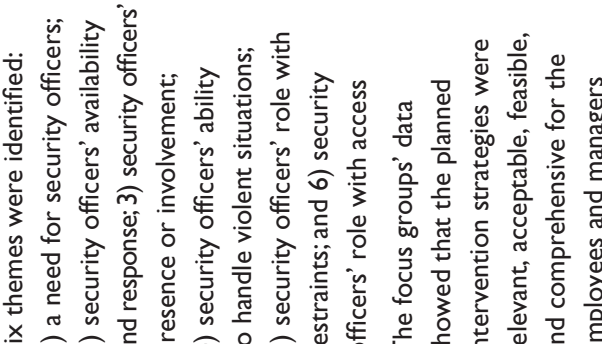
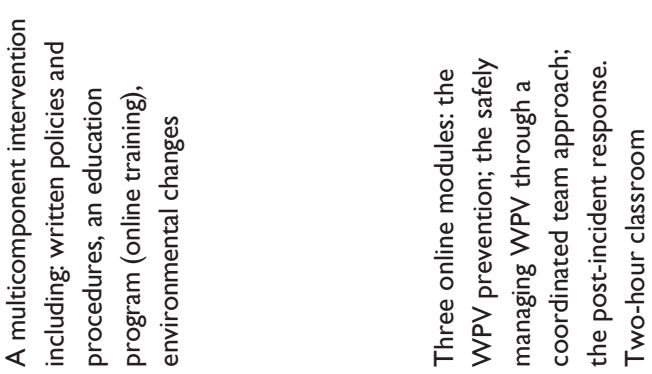

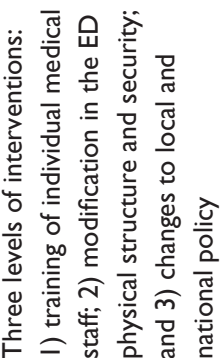

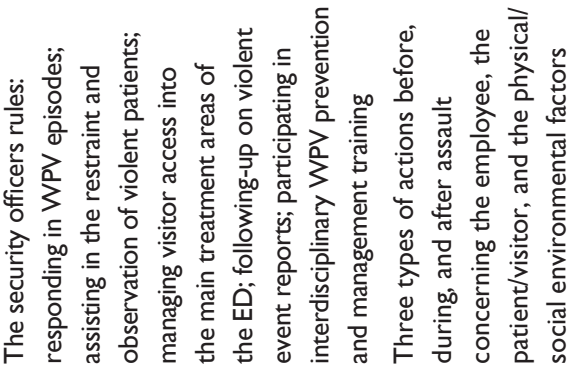

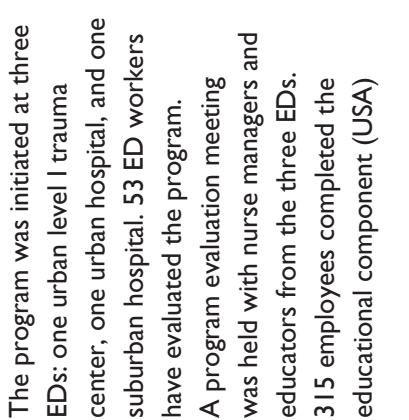
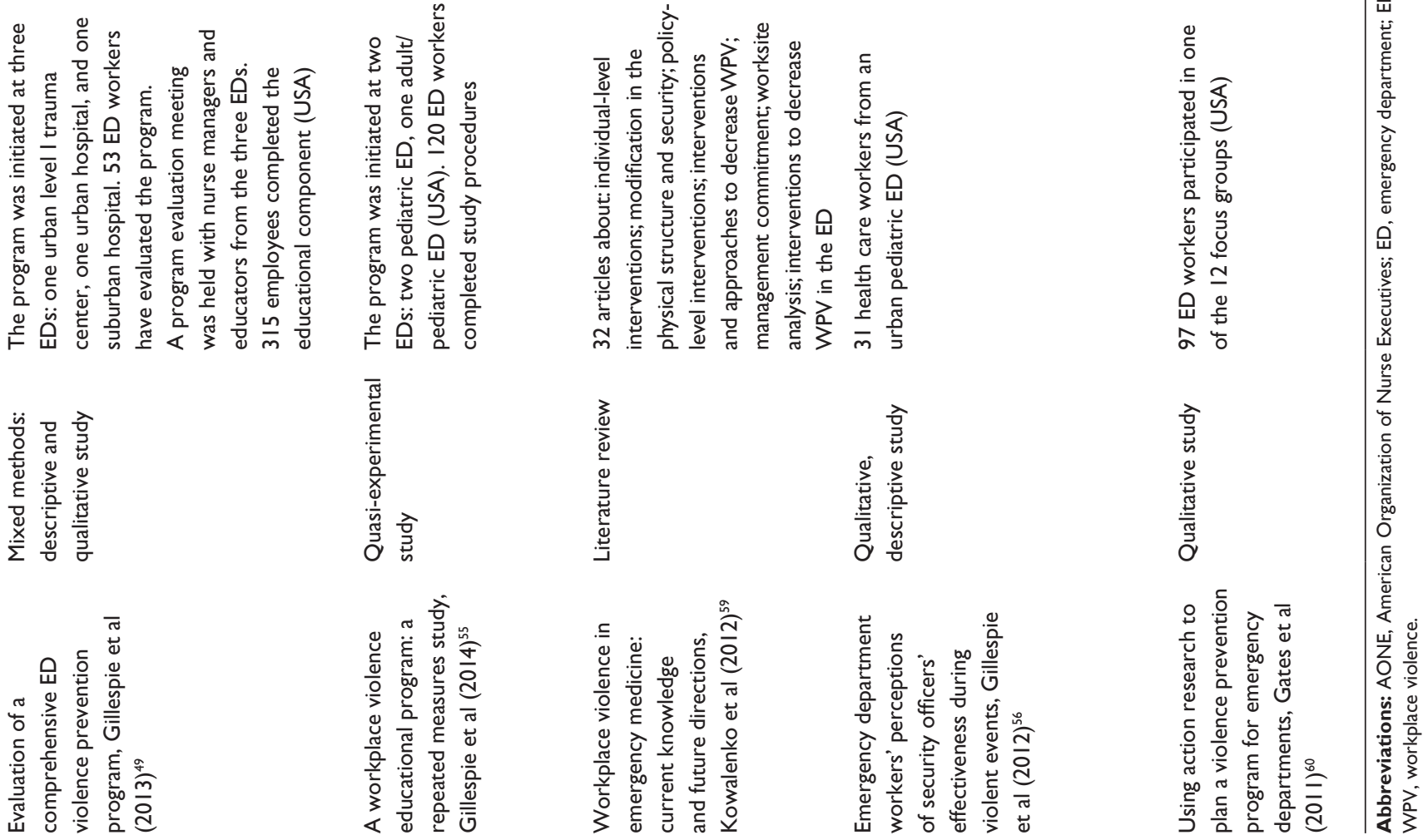

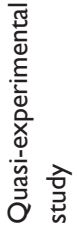
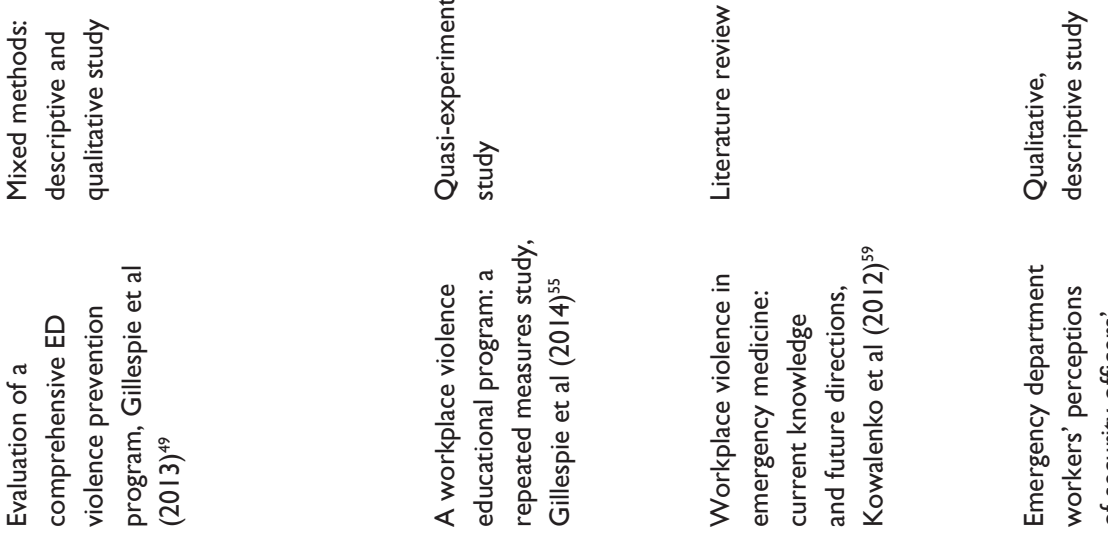
Day of Dialogue on Mitigating Violence in the Workplace proposed eight guiding principles for mitigating WPV (Table 4) and five focus areas for health care organizations: encouraging respectful communication and behavior, establishing a zero-tolerance policy, ensuring ownership and accountability, offering training and education on WPV, and creating outcome metrics of the program's success. This toolkit and the guiding principles can assist health care professionals (ED managers, nurses, or physicians) in implementing and applying useful approaches for systematically reducing patient and family/caregiver violence in hospitals.

\section{Scenario-based training methods}

Kotora et al, ${ }^{52}$ in-line with the fifth point of the fourth priority focus area (Table 4), recently proposed a simulation

Table 4 Guiding principles on mitigating violence in the workplace and five priority focus areas

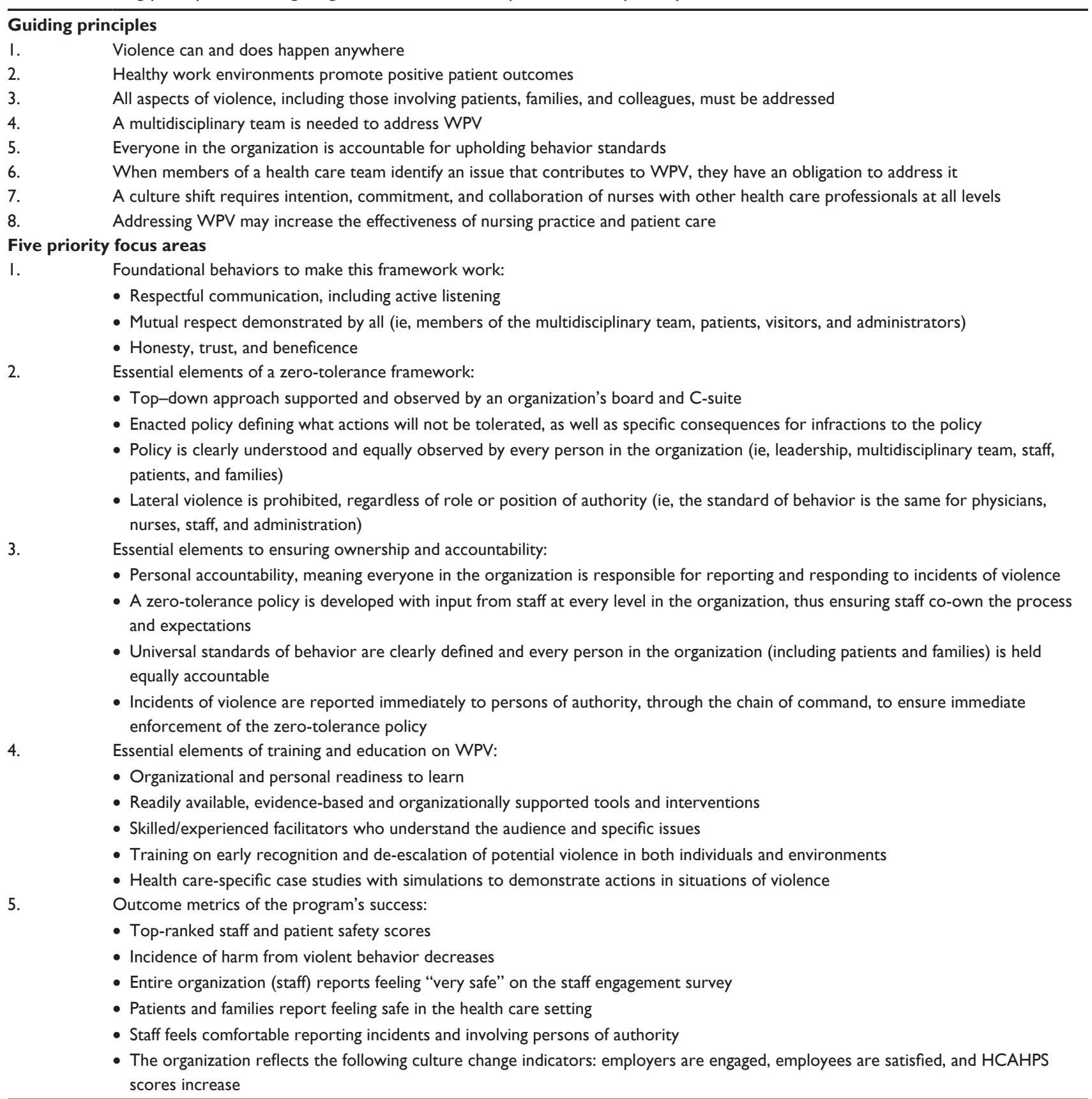

Notes: Reprinted from the Journal of Emergency Nursing; 4I (4); American Organization of Nurse Executives; Emergency Nurses Association; AONE and ENA develop guiding principles on mitigating violence in the workplace; 278-280; Copyright (C) 2015 Elsevier; with permission from Elsevier. ${ }^{34}$

Abbreviations: WPV, workplace violence; HCAHPS, Hospital Consumer Assessment of Healthcare Providers and Systems. 
training approach using health-care-specific case studies with simulations to enhance behavioral awareness in situations of violence which they see as an essential element of training and education on WPV. The authors constructed a comprehensive training experience to better prepare health care workers for an active shooter (an extreme situation that may occur in the ED) using didactic and scenario-based training methods. After completing a ten-item pretest developed by the Department of Homeland Security's IS:907 Active Shooter course, 32 resident nursing and medical students participated in a single shooting scenario simulation followed by a lecture on hostage recovery and crisis negotiation. They were then exposed to simulated multiple shooting. A post-test and debrief concluded the stage. Didactic lectures combined with case-based scenarios have proven effective in teaching health care workers how to best manage an active shooting incident. In fact, the paired Student's $t$-tests confirmed a statistically significant difference between the pre- and post-test scores for all the participants $(P<0.002$ $[-0.177,-0.041])$.

\section{Rapid training program}

Educational interventions that aim to promote effective communication skills and use of de-escalation techniques to prevent patient aggression are certainly a useful strategy (the fifth point of fourth priority area in Table 4). The approach proposed by Gerdtz et $\mathrm{al}^{53}$ aims to provide this type of expertise quickly and widely. Their study published in 2013 was conducted to evaluate the effectiveness of their proposed intervention, based on the theoretical model of Duxbury, ${ }^{54}$ that divides the causal factors for patient aggression into three categories: internal (patient/biomedical causes), external (environmental causes), and interactional (situational causes). The Management of Clinical Aggression - Rapid Emergency Department Intervention is a rapid training course, which is delivered over a 45-minute staff in-service session. The Australian authors have tested this program with a mixed approach: both with a pre- and post-test administered to trainee participants immediately before and 6-8 weeks after training, and with individual interviews of managers and trainees 8-10 weeks after the intervention. This involved three key learning activities: 1) viewing of a 3.5-minute DVD simulation of an episode of patient aggression in the ED; 2) discussion on research evidence regarding the prevention of aggression in health care settings, risk factors for WPV, and early warning signs for aggression; and 3) review of the current approaches used to manage episodes of aggression in the workplace and discussion on the ways in which practice may be improved. A total of 471 participants from 18 EDs located in Victoria completed the pre- and post-test after training. Twenty-eight managers and trainers provided their perceptions of the impact of the program. Despite undergoing training, the participants reported feeling unsure about whether or not it would be possible to prevent episodes of patient aggression (statistically significant shifts were only observed in five of 23 items). However, qualitative changes were reported by managers in the way some members of staff worked to prevent episodes of patient aggression during practice.

\section{Hybrid educational intervention}

Prevention-focused education is considered by many authors to be a major strategy in reducing the risk of violence in the ED. The likelihood of achieving significant learning outcomes and retention by the use of a hybrid (online and classroom) educational program was recently demonstrated by Gillespie et al. ${ }^{55}$ In this study, the authors tested an educational approach that covered the topics usually proposed in programs of this kind with three online modules: the prevention of WPV (environmental safety, risk assessment, and communicating effectively with patients and visitors), the safe management of WPV through a coordinated team approach, and the post-incident response (incident reporting and caring for victimized workers). After a 2-hour interactive classroom session, the participants held a discussion with their colleagues on how to best manage the WPV events. Thanks to a quasi-experimental study, which enrolled 143 nurses (120 of whom formed the study sample) from the two US EDs, the effectiveness of the educational program was evaluated by three tests (at baseline, post-test, and 6-month post-test). A significant time effect was observed in the results obtained from a repeated-measures analysis of variance carried out to determine whether individual test scores increased significantly over time. The authors concluded that this type of educational prevention program on WPV tailored to the needs of ED employees can be a useful strategy for the achievement of satisfactory learning outcomes.

\section{Rapid response teams}

The presence of security guards in the ED is widely considered effective in reducing violent episodes, but few studies have evaluated the role and the impact of security officers to contrast WPV. Gillespie et $\mathrm{al}^{56}$ in their qualitative study published in 2012 tried to fill this gap. An alternative approach is proposed by Kelley ${ }^{57}$ in her study, where the security officers are placed in a rapid response team consisting of physicians, nurses, social workers, technicians, human resources personnel, members of administration, and risk management personnel. According to 
the study by Gillespie et al, the support offered by the security officers (not only limited to the rapid actions required when a patient or visitor becomes violent but also including assisting in the restraint and observation of violent patients, managing visitors on arrival in the ED, following-up on violent event reports, participating in interdisciplinary WPV prevention, and management training) is perceived by the emergency staff as valid and useful, although their effectiveness in maintaining a safe work environment is not perceived. ${ }^{56}$ Similarly, Kelley's research highlights the usefulness of introducing a multidisciplinary de-escalation team to provide the best response to violent behavior of patients and visitors. ${ }^{57}$

\section{Comprehensive approach}

Gillespie et al, ${ }^{58}$ who have carried out a lot of pertinent research, suggest that an effective approach to reduce physical assaults and threats in the ED must be based on comprehensive intervention. Implementing any necessary environmental changes, laying down policies and procedures, and offering education and training are the three fundamental interventions benefitting all staff members, no matter what their role is (physicians, nurses, social workers, security officers, registrars, psychologists, and risk managers). Continuous feedback from employees, managers, and administrators, and the advice of experts in WPV prevention and management are crucial for the success of this type of preventive action. Although, in their study, the hypothesis that the intervention sites would have a significantly greater decrease in WPV episodes compared to control sites was not supported, the authors note that two out of three intervention sites recorded a significant decrease in violent events.

Similarly, in the overview of interventions for WPV in the ED recently proposed by Kowalenko et al, ${ }^{59}$ multiple approaches are suggested: training individual medical staff members; modification of the physical structure and security of the ED, and changes to local (institutional/regional) and national policies or action plans aimed at reducing violence in the ED. Unfortunately, this review of the literature shows that there is still no evidence of effectiveness for any of the proposed actions.

\section{Action research approach}

The complexity of the phenomenon of WPV can be addressed with an actions research approach. This is the strategy proposed by Gates et al. ${ }^{60}$ The researchers have used the Haddon matrix, ${ }^{61}$ which combines the epidemiologic concepts of host, vehicle, agent/vector, and environment with the concepts of primary, secondary, and tertiary prevention, to identify and categorize their intervention strategies for reducing episodes of aggression in the ED (Table 5).

Table 5 The Haddon matrix applied to ED violence prevention

\begin{tabular}{|c|c|c|c|}
\hline & $\begin{array}{l}\text { Host (employee) } \\
\text { factors }\end{array}$ & $\begin{array}{l}\text { Vector and vehicle } \\
\text { (patient/visitor) factors }\end{array}$ & Physical/social environmental factors \\
\hline Before assault & $\begin{array}{l}\text { - Education and training } \\
\text { - Policy and procedures } \\
\text { - Preventing aggressive } \\
\text { - Behaviour de-escalation } \\
\text { and conflict resolution } \\
\text { - Managing aggression }\end{array}$ & $\begin{array}{l}\text { - Communication to patients and } \\
\text { visitors of policy that violence will } \\
\text { not be tolerated and potential } \\
\text { consequences of violent behavior } \\
\text { - Minimize anxiety for waiting } \\
\text { patients and visitors by } \\
\text { communicating with them } \\
\text { every } 30 \text { min }\end{array}$ & $\begin{array}{l}\text { - Develop and communicate policy to employees and } \\
\text { management that violence is never acceptable } \\
\text { - Development and implementation of violence } \\
\text { policies and procedures } \\
\text { - Manager education } \\
\text { - Security/police response/policies and education } \\
\text { - Monitor access to emergency department } \\
\text { - Develop mechanism to alert staff when patients } \\
\text { and visitors who were previously violent visit the } \\
\text { emergency department again } \\
\text { - Quiet environment/areas } \\
\text { - Special area for aggressive individuals/safe room } \\
\text { for criminals } \\
\text { - Enforce visitor policies (ie, number of visitors) }\end{array}$ \\
\hline During Assault & $\begin{array}{l}\text { - Education and training } \\
\text { - Nonviolent crisis } \\
\text { intervention }\end{array}$ & - Isolate perpetrator from others & $\begin{array}{l}\text { - Security/police plan } \\
\text { - Implement procedures for dealing with violent event } \\
\text { - Create procedure for investigating physical threats }\end{array}$ \\
\hline After Assault & $\begin{array}{l}\text { - Critical incident debriefing } \\
\text { - Mandatory reporting of all } \\
\text { physical assaults and } \\
\text { physical threats }\end{array}$ & $\begin{array}{l}\text { - Reporting to security/police } \\
\text { - Maintain patient's/visitor's name } \\
\text { for alerting staff upon return visit }\end{array}$ & - Create procedure for reviewing violent event \\
\hline
\end{tabular}

Note: Reprinted from The Journal of Emergency Nursing; 37(I); Gates D, Gillespie G, Smith C, Rode J, Kowalenko T, Smith B. Using action research to plan a violence prevention program for emergency departments; 32-39; Copyright (C 201 I Emergency Nurses Association. Published by Elsevier Inc. All rights reserved; with permission from Elsevier. ${ }^{60}$

Abbreviation: ED, emergency department. 
The results of the qualitative study conducted by the authors with 97 members of staff who participated in 12 focus groups showed that the planned intervention strategies were relevant, acceptable, feasible, and comprehensive for both employees and managers.

\section{Conclusion}

The phenomenon of WPV in the health sector, and in the ED in particular, is the subject of numerous international studies. Interesting theoretical models ${ }^{54,62}$ and explanatory frameworks ${ }^{63}$ have been developed. Understanding the types of violent acts (verbal or physical) and the perpetrators (patients, their relatives, or their friends), highlighting the precipitants and risk factors, and quantifying the phenomenon are among the main objectives of many papers. These studies are generally analytical and descriptive, usually with a mixed qualitative/quantitative methodology ${ }^{64}$ Some of these have focused on intervention strategies to address the violence against health care workers. Moreover, the few studies that have attempted to evaluate the effectiveness of interventions have shown weak evidence to date. Further research is needed to identify effective training content, best practices, and security measures designed to promote a safe work environment in the ED. We think that the complexity of the phenomenon and the strong interrelation between various factors suggest that the problem of violence in the ED could be effectively faced only with multiple strategies based on "multidimensional" analysis of the operating ambiences and interventions.$^{65}$ Global ${ }^{10}$ and interdisciplinary ${ }^{66}$ approaches for managing aggression in the ED will allow us to find effective solutions. The biggest challenge is to ensure that violence against health professionals does not "come with the job" 67 and ceases to be considered "part of our job" ${ }^{68}$

\section{Disclosure}

The authors report no conflicts of interest in this work.

\section{References}

1. Ray MM. The dark side of the job: violence in the emergency department. J Emerg Nurs. 2007;33(3):257-261.

2. National Institute of Occupational Safety and Health (NIOSH) [webpage on the Internet]. Violence: Occupational Hazards in Hospitals. Department of Health and Human Services. Vol. 101. 2002:1-10. Available from: http:// www.cdc.gov/niosh/docs/2002-101/. Accessed November 22, 2015.

3. Gates DM. The epidemic of violence against healthcare workers. Occup Environ Med. 2004;61(8):649-650.

4. Chapman R, Styles I. An epidemic of abuse and violence: nurse on the front line. Accid Emerg Nurs. 2006;14(4):245-249.

5. Whelan T. The escalating trend of violence toward nurses. J Emerg Nurs. 2008;34(2):130-133.

6. American Nurses Association. Workplace violence against emergency nursing remains high. Am Nurse. 2011;43(6):7.
7. International Labour Office; International Council of Nurses; World Health Organization; Public Services International [webpage on the Internet]. Framework Guidelines for Addressing Workplace Violence in the Health Sector. 2015. Available from: http://www.who.int/violence_ injury_prevention/violence/interpersonal/en/WVguidelinesEN.pdf. Accessed November 22, 2015.

8. Wu JC, Tung TH, Chen PY, Chen YL, Lin YW, Chen FL. Determinants of workplace violence against clinical physicians in hospitals. J Occup Health. Epub 2015 Sep 29.

9. Baydin A, Erenler AK. Workplace violence in emergency department and its effects on emergency staff. Int $J$ Emerg Ment Health. 2014;16(2):288-290.

10. Ramacciati N, Ceccagnoli A, Addey B. Violence towards nurses in the Triage area. Scenario. 2013;30(4):4-10.

11. Wyatt JP, Watt M. Violence towards junior doctors in accident and emergency departments. J Accid Emerg Med. 1995;12:40-42.

12. Lyneham J. Violence in New South Wales emergency departments. Aust J Adv Nurs. 2000;18(2):8-17.

13. Behnam M, Tillotson RD, Davis SM, Hobbs GR. Violence in the emergency department: a national survey of emergency medicine residents and attending physicians. J Emerg Med. 2011;40(5):565-579.

14. Lee F. Violence in A\&E: the role of training and self-efficacy. Nurs Stand. 2001;15(46):33-38.

15. Crilly J, Chaboyer W, Creedy D. Violence towards emergency department nurses by patients. Accid Emerg Nurs. 2004;12(2):67-73.

16. Winstanely S, Whittington R. Aggression towards health care staff in a UK general hospital: variation among professions and departments. J Clin Nurs. 2004;13(1):3-10.

17. James A, Madeley R, Dove A. Violence and aggression in the emergency department. Emerg Med J. 2006;23(6):431-434.

18. Cezar ES, Marziale MH. Problemas de violência ocupacional em um serviço de urgência hospitalar da Cidade de Londrina, Paraná, Brasil. [Occupational violence problems in an emergency hospital in Londrina, Paraná, Brazil]. Cad Saude Publica. 2006;22(1):217-221. [Portuguese].

19. Ryan D, Maguire J. Aggression and violence - a problem in Irish accident and emergency departments? J Nurs Manag. 2006;14(2):106-115.

20. Pinar R, Ucmak F. Verbal and physical violence in emergency departments: a survey in Istanbul, Turkey. J Clini Nurs. 2011;20(3-4):510-517.

21. Esmaeilpour M, Salsali M, Ahmadi F. Workplace violence against Iranian nurses working in emergency departments. Int Nurs Rev. 2011;58(1):130-137.

22. Pich J, Hazelton M, Sundin D, Kable A. Patient related violence at triage: a qualitative descriptive study. Int Emerg Nurs. 2011;19(1):12-19.

23. Jones J, Lyneham J. Violence: part of the job for Australian nurses? Aust J Adv Nurs. 2000;18(2):27-32.

24. Saines JC. Violence and aggression in A\&E: recommendations for action. Accid Emerg Nurs. 1999;7:8-12.

25. Gascon S, Martinez-Jarreta B, Gonzalez-Andrade JF, Santed MA, Casalod Y, Rueda MA. Aggression towards health care workers in Spain: a multi-facility study to evaluate the distribution of growing violence among professionals, health facilities and departments. Int $J$ Occup Environ Health. 2009; 15:29-35.

26. Ramacciati N, Ceccagnoli A, Addey B. Violenza e aggressioni in Pronto Soccorso: revisione della letteratura. [Violence and aggression in the emergency department: a literature review]. L'Infermiere. 2011;48(5):e43-e50. [Italian].

27. Fernandes CM, Bouthillette F, Raboud JM, et al. Violence in the emergency department: a survey of health care workers. CMAJ. 1999;161(10):1245-1248.

28. Gacki-Smith J, Juarez AM, Boyett L, Homeyer C, Robinson L, MacLean SL. Violence against nurses working in US emergency departments. J Healthc Prot Manage. 2010;26(1):81-89.

29. Zafar W, Khan UR, Siddiqui SA, Jamali S, Razzak JA. Workplace violence and self-reported psychological health: coping with post-traumatic stress, mental distress, and burnout among physicians working in the emergency departments compared to other specialties in Pakistan. J Emerg Med. 2016;50(1):167.e1-177.e1. 
30. AL Bashtawy M, Aljezawi M. Emergency nurses' perspective of workplace violence in Jordanian hospitals: a national survey. Int Emerg Nurs. 2016;24:61-65.

31. Darawad MW, Al-Hussami M, Saleh AM, Mustafa WM, Odeh H. Violence against nurses in emergency departments in Jordan: nurses' perspective. Workplace Health Saf. 2015;63(1):9-17.

32. Ramacciati N, Ceccagnoli A, Addey B. Violence against nurses in the triage area: an Italian qualitative study. Int Emerg Nurs. 2015;23(4):274-280.

33. Chappell S. The American Organization of Nurse Executives and Emergency Nurses Association guiding principles on mitigating violence in the workplace. J Nurs Adm. 2015;45(7-8):358-360.

34. American Organization of Nurse Executives; Emergency Nurses Association. AONE and ENA develop guiding principles on mitigating violence in the workplace. J Emerg Nurs. 2015;41(4):278-280.

35. Renker P, Scribner SA, Huff P. Staff perspectives of violence in the emergency department: appeals for consequences, collaboration, and consistency. Work. 2015;51(1):5-18.

36. Shaw J. Staff perceptions of workplace violence in a pediatric emergency department. Work. 2015;51(1):39-49.

37. Burchill C. Development of the personal workplace safety instrument for emergency nurses. Work. 2015;51(1):61-66.

38. Stene J, Larson E, Levy M, Dohlman M. Workplace violence in the emergency department: giving staff the tools and support to report. Perm J. 2015;19(2):e113-e117.

39. Morken T, Johansen IH, Alsaker K. Dealing with workplace violence in emergency primary health care: a focus group study. BMC Fam Pract. 2015;16:51.

40. Hogarth KM, Beattie J, Morphet J. Nurses' attitudes towards the reporting of violence in the emergency department. Australas Emerg Nurs J. Epub 2015 May 23.

41. Hamdan M, Abu Hamra A. Workplace violence towards workers in the emergency departments of Palestinian hospitals: a cross-sectional study. Hum Resour Health. 2015;13:28.

42. Fute M, Mengesha ZB, Wakgari N, Tessema GA. High prevalence of workplace violence among nurses working at public health facilities in Southern Ethiopia. BMC Nurs. 2015;14:9.

43. Eslamian J, Akbarpoor AA, Hoseini SA. Quality of work life and its association with workplace violence of the nurses in emergency departments. Iran J Nurs Midwifery Res. 2015;20(1):56-62.

44. Tan MF, Lopez V, Cleary M. Nursing management of aggression in a Singapore emergency department: a qualitative study. Nurs Health Sci. 2015;17(3):307-312.

45. Vezyridis P, Samoutis A, Mavrikiou PM. Workplace violence against clinicians in Cypriot emergency departments: a national questionnaire survey. J Clin Nurs. 2015;24(9/10):1210-1222.

46. Casalino E, Choquet C, Thomas S, Erhel S, Cossard P. La violence dans les services d'urgences: évaluation d'une politique de réduction de la violence dans un service d'accueil des urgences parisien [Violence in emergency services: evaluation of a violence reduction policy in a host of Parisian Emergency Service]. Annales françaises de médecine d'urgence. 2015;5(4):226-237. [French].

47. Rees S, Evans D, Bower D, Norwick H, Morin T. A program to minimize ED violence and keep employees safe. J Emerg Nurs. 2010;36(5):460-465.

48. Wassel JT. Workplace violence intervention effectiveness: a systematic literature review. Saf Sci. 2009;47:1049-1055.

49. Gillespie GL, Gates DM, Mentzel T, Al-Natour A, Kowalenko T. Evaluation of a comprehensive ED violence prevention program. J Emerg Nurs. 2013;39(4):376-383.

50. Christie W. The Lived Experience: How Emergency Department Nurses Resolve Emotional Pain After Patient Perpetrated Workplace Violence [Doctoral dissertation]. Little Rock: University of Arkansas for Medical Sciences; 2014.
51. Gacki-Smith J, Juarez AM, Boyett L, Homeyer C, Robinson L, MacLean SL. Violence against nurses working in US emergency departments. J Nurs Adm. 2009;39(7-8):340-349.

52. Kotora JG, Clancy T, Manzon L, Malik V, Louden RJ, Merlin MA. Active shooter in the emergency department: a scenario-based training approach for healthcare workers. Am J Disaster Med. 2014;9(1): 39-51.

53. Gerdtz MF, Daniel C, Dearie V, Prematunga R, Bamert M, Duxbury J. The outcome of a rapid training program on nurses' attitudes regarding the prevention of aggression in emergency departments: a multi-site evaluation. Int J Nurs Stud. 2013;50(11):1434-1445.

54. Duxbury J. An exploratory account of registered nurses' experience of patient aggression in both mental health and general nursing settings. J Psychiatr Ment Health Nurs. 1999;6(2):107-114.

55. Gillespie GL, Farra SL, Gates DM. A workplace violence educational program: a repeated measures study. Nurse Educ Pract. 2014; 14(5):468-472.

56. Gillespie GL, Gates DM, Miller M, Howard PK. Emergency department workers' perceptions of security officers' effectiveness during violent events. Work. 2012;42(1):21-27.

57. Kelley EC. Reducing violence in the emergency department: a rapid response team approach. J Emerg Nurs. 2014;40(1):60-64.

58. Gillespie GL, Gates DM, Kowalenko T, Bresler S, Succop P. Implementation of a comprehensive intervention to reduce physical assaults and threats in the emergency department. J Emerg Nurs. 2014;40(6):586-591.

59. Kowalenko T, Cunningham R, Sachs CJ, et al. Workplace violence in emergency medicine: current knowledge and future directions. J Emerg Med. 2012;43(3):523-531.

60. Gates D, Gillespie G, Smith C, Rode J, Kowalenko T, Smith B. Using action research to plan a violence prevention program for emergency departments. J Emerg Nurs. 2011;37(1):32-39.

61. Haddon W. Advances in the epidemiology of injuries as a basis for public policy. Public Health Rep. 1980;95(5):411-421.

62. Ferns T. Considering theories of aggression in an emergency department context. Accid Emerg Nurs. 2007;15(4):193-200.

63. Ramacciati N, Ceccagnoli A, Addey B. Wellbeing at work: going towards a global approach to violence in the ER. Scenario. 2013;30(2):S51-S52.

64. Brunetti L, Bambi S. Le aggressioni nei confronti degli infermieri dei dipartimenti di emergenza: revisione della letteratura internazionale. [Aggressions towards nurses in emergency departments: an international literature review]. Prof Inferm. 2013;66(2): 109-116. [Italian].

65. Ramacciati N, Ceccagnoli A, Addey B, Giusti GD. Comment on: "Nurses' perceptions of the factors which cause violence and aggression in the emergency department: a qualitative study". Int. Emerg. Nurs. 22(3) (2014), 134-139 by Angland, S., et al. Int Emerg Nurs. 2014;22(4):232-233.

66. Rintoul Y, Wynaden D, McGowan S. Managing aggression in the emergency department: promoting an interdisciplinary approach. Int Emerg Nurs. 2009;17(2):122-127.

67. Dubb SS. It doesn't "come with the job": violence against doctors at work must stop. BMJ. 2015;350:h2780.

68. Baby M, Glue P, Carlyle D. 'Violence is not part of our job': a thematic analysis of psychiatric mental health nurses' experiences of patient assaults from a New Zealand perspective. Issues Ment Health Nurs. 2014;35(9):647-655. 
Open Access Emergency Medicine

Dovepress

\section{Publish your work in this journal}

Open Access Emergency Medicine is an international, peer-reviewed, open access journal publishing original research, reports, editorials, reviews and commentaries on all aspects of emergency medicine. The manuscript management system is completely online and includes a very quick and fair peer-review system, which is all easy to use.

Submit your manuscript here: http://www.dovepress.com/open-access-emergency-medicine-journal
Visit http://www.dovepress.com/testimonials.php to read real quotes from published authors. 